\title{
ABORDAGEM SISTÊMICA E A GEODIVERSIDADE: CONCEITUAÇÃO E BREVE CONSIDERAÇÃO TEÓRICO- METODOLÓGICA
}

\author{
Gabriel Flora Vieira ${ }^{1}$ \\ Paulo Henrique de Souza ${ }^{2}$ \\ Raphaela A. de Oliveira Araujo ${ }^{3}$
}

RESUMO: A análise metodológica sob um prisma sistêmico tem início de forma organizada nas primeiras décadas do século XX, e, após a década de 1950, Ludwing Von Bertalanffy em seu livro intitulado "General System Theory" apresenta um novo paradigma para se compreender o objeto passível de análise, rompendo com o cartesianismo mecanicista e propondo uma investigação da totalidade dos elementos e suas inter-relações. De igual forma, estudos em Geodiversidade também são recentes e ainda em processo de construção, por mais que a temática esteja vinculada à necessidade de proteção e inventário da diversidade abiótica terrestre que constituem as bases para o desenvolvimento da vida e produção do espaço pelo homem. Dentro dessas concepções, este artigo procura apresentar considerações sobre os vínculos intrínsecos dos estudos em Geodiversidade para com a abordagem sistêmica, explicitando técnicas utilizadas neste campo de pesquisa e destacando as contribuições que as pesquisas formatadas sob este escopo metodológico proporcionam para o avanço da Ciência Geográfica no entendimento da paisagem e do papel que cada elemento constituinte possui isoladamente e de forma articulada dentro da perspectiva de uma totalidade que contempla inclusive os componentes antrópicos.

PALAVRAS-CHAVE: Teoria Geral do Sistema; Ciência; Objeto; Análise; Pesquisa.

\section{SYSTEMIC APPROACH AND GEODIVERSITY: CONCEPT AND BRIEF THEORETICAL-METHODOLOGICAL CONSIDERATION}

\footnotetext{
ABSTRACT: The methodological analysis from a systemic perspective begins in an organized way in the first decades of the 20th century, and, after the 1950s, Ludwing Von Bertalanffy in his book entitled "General System Theory" presents a new paradigm for understanding the object subject to analysis, breaking with the mechanistic Cartesianism

${ }^{1}$ Mestrando do PPGEO da UNIFAL-MG; gabriel.flora@sou.unifal-mg.edu.br

2 Professor Associado do ICN e do PPGEO da UNIFAL-MG; paulohenrique.souza@unifalmg.edu.br

${ }^{3}$ Mestranda do PPGEO da UNIFAL-MG; raphaela.araujo@sou.unifal-mg.edu.br
} 
and proposing an investigation of the totality of the elements and their interrelationships. Likewise, studies in Geodiversity are also recent and still in the process of construction, even though the theme is linked to the need for protection and inventory of terrestrial abiotic diversity that constitute the bases for the development of life and production of space by man. Within these concepts, this article seeks to present considerations on the intrinsic links of studies in Geodiversity to the systemic approach, explaining techniques used in this field of research and highlighting the contributions that research formatted under this methodological scope provide for the advancement of Geographical Science in the understanding of the landscape and the role that each constituent element has in isolation and in an articulated way within the perspective of a totality that includes even the anthropic components.

KEYWORDS: General System Theory; Science; Object; Analysis; Research.

\section{ENFOQUE SISTÉMICO Y GEODIVERSIDAD: CONCEPTO Y BREVE CONSIDERACIÓN TEÓRICO-METODOLÓGICA}

RESUMEN: El análisis metodológico desde una perspectiva sistémica se inició de forma organizada en las primeras décadas del siglo XX y, a partir de la década de 1950, Ludwing Von Bertalanffy, en su libro titulado "Teoría general de sistemas", presenta un nuevo paradigma para entender el tema que puede ser el análisis, rompiendo con el cartesianismo mecanicista y proponiendo una investigación de la totalidad de los elementos y sus interrelaciones. Asimismo, los estudios en Geodiversidad también son recientes y aún en proceso de construcción, aunque el tema está vinculado a la necesidad de protección e inventario de la diversidad abiótica terrestre que constituyen las bases para el desarrollo de la vida y producción del espacio por parte del hombre. Dentro de estos conceptos, este artículo busca presentar consideraciones sobre los vínculos intrínsecos de los estudios en Geodiversidad con el enfoque sistémico, explicando las técnicas utilizadas en este campo de investigación y destacando los aportes que las investigaciones formateadas bajo este ámbito metodológico brindan para el avance de la Ciencia Geográfica en la comprensión del paisaje y el papel que cada elemento constituyente tiene de forma aislada y articulada dentro de la perspectiva de una totalidad que incluye incluso los componentes antrópicos.

PALABRAS CLAVE: Teoría General de Sistemas; Ciencias; Objeto; Análisis; Investigación.

\section{INTRODUÇÃO}

A Teoria Geral dos Sistemas proposta por Bertalanffy (1973), além de revolucionar as pesquisas no campo ao qual foi proposta, a saber, a Biologia, 
acabou por impactar diretamente toda a Ciência moderna, incluindo a Geografia, pois o entendimento amplo proporcionado pela metodologia sistêmica em contraposição ao modelo existente, proporcionou à Ciência Geográfica uma maior compreensão da relação estabelecida entre os objetos que a compõem, uma vez que o cartesianismo visava compreender o todo por meio da divisão dos elementos e pela ampla preconização da razão, por vezes matemática (LIMBERGER, 2006).

Tal contribuição encontrou-se inserida no bojo das reformulações e modificações que ocorrem nas linhas de pesquisa e se manifestam paulatinamente nos diversos estudos dentro do escopo natural e positivo da evolução da Ciência, ressaltando-se em especial que na Geografia esse processo acompanhou suas diversas discussões identitárias ocupadas com as formas de analisar seu objeto de estudo e os métodos para compreendê-lo, o que por sua vez culminou nos períodos geográficos.

De tais períodos, pode-se citar, a Geografia Clássica de cunho parte determinista por seus pensadores como Humboldt e Ratzel e parte possibilista por expoentes como La Blache. Também é possível ressaltar o período de maior afinidade para com a matemática e a estatística, pautado pela compreensão do espaço por meio de quantificações, com a Geografia Quantitativa; assim como visões mais complexas voltadas para o social e a relação da Geografia para com a luta de classes, por meio da Geografia Crítica; destacando, por conseguinte, uma permanente adequação e releitura em sua forma de analisar o espaço através dos diversos métodos empregados por seus pesquisadores.

Neste aspecto, a Teoria Geral dos Sistemas (TGS) traz como proposta no âmbito da Geografia, a compreensão de um meio natural complexo, hierárquico e sistêmico, no qual o homem também se encontra incluso, pois, segundo entende Bertalanffy (1973), tinha como premissa a proposição de um novo conceito, uma epistéme complexa, na qual a linguagem científica fosse única, 
podendo de certa forma englobar todos os campos do conhecimento, construindo uma totalidade. (BERTALANFFY, 1973; VICENTE; PEREZ FILHO, 2003).

Uma vez que a sociedade tem voltado seus olhos para a paisagem sob o viés de sua Biodiversidade que contempla a Geodiversidade devido as questões ambientais que repercutem sobre as condições de vida da população, ou econômicas que se sobressaem pelos empregos e renda gerada através do Geoturismo que constitui segmento do turismo voltado para áreas naturais (MOREIRA, 2010); a Geodiversidade, portanto, possui relevância inerente na totalidade que compõe a paisagem e inclui os aspectos antropogênicos.

Nesta compreensão, este artigo explicitará o método sistêmico e sua inserção na Geografia, buscando evidenciar sua aplicação nos estudos em Geodiversidade, bem como, as práticas necessárias para a efetivação da pesquisa utilizando duas técnicas; o geoprocessamento ou geodiversidade cartográfica e o trabalho de campo.

\section{TEORIA GERAL DOS SISTEMAS: QUESTÕES INTRODUTÓRIAS}

A busca pela compreensão do mundo influenciou diversos pensadores ao longo da História Antiga como Aristóteles e Platão, gerando teorias capazes de explicar fenômenos, acontecimentos, comportamentos humanos e verdades momentâneas.

Durante o Medievo a observação ficou relegada a um segundo plano devido à presença incisiva da religião, principalmente da Igreja Católica Romana, abrindo espaço para a influência dos dogmas e metafísica nas concepções e descobertas científicas. Isso foi feito, sobretudo, através de pensadores como Agostinho e Tomás de Aquino, responsáveis por resinificar os conhecimentos científicos conforme os pressupostos da Igreja. (VICENTE; PEREZ FILHO, 2003).

Com o "renascimento científico" após o lluminismo, figuras como René 
Descartes se apresentam e trazem consigo pensamentos voltados para uma Ciência que passasse sempre pelo crivo da razão e da comprovação. Este modelo que presava, sobretudo, pelo questionamento de leis naturais e a compartimentação do objeto de estudo por onde se observaria o entendimento do elemento como um todo, ficou conhecido como cartesianismo ou mecanicismo (VICENTE; PEREZ FILHO, 2003).

Segundo os autores citados, essa nova forma de se analisar o mundo tinha como lógica absoluta a razão, a análise de dados sensíveis, e, a empiria, mudando, portanto, a relação imposta no medievo a qual se dava pela visão Deus-homem para uma relação homem-natureza. Tal modelo teve como principais expoentes, Galileu Galilei, Francis Bacon (preconizou o método empírico-indutivo), René Descartes (preconizou o método racional-dedutivo) e Isaac Newton, que colaborou com as proposições físico-matemáticas.

Entretanto, tal método não dava conta de explicar a complexidade imposta pela realidade; na qual a simples compartimentação para estudos não seria fidedigna o suficiente (VICENTE; PEREZ FILHO, 2003). Segundo Morin (1997, p. 83), a compreensão científica pautada no cartesianismo "não tinha singularidade em sua obediência às leis gerais, factualidade em seus movimentos repetitivos de relógio". Sob essa ótica, uma compreensão parcial passa a ser obtida devido a desconsideração do todo quando é procedida a compartimentação do objeto, permitindo uma leitura equivocada de sua verdadeira funcionalidade e função.

Tendo isso em vista, fez-se possível a proposição de um método que compreendesse o objeto em toda sua totalidade após as preconizações feitas por Defay na década de 1930 e posteriormente por Bertalanffy. Diante da proposição dos autores, seu objetivo inicial consistia em buscar uma linguagem científica única que englobasse todos os campos do conhecimento (BERTALANFFY, 1973). 
Segundo este pesquisador, não existia a princípio a preocupação de se apresentar uma definição em específico do que vinha a ser um sistema. Entretanto, diversos autores se debruçaram sobre a temática e chegaram à algumas compreensões; assim como ele mesmo ao designar o sistema como "um conjunto de elementos em interação". Para Maturana et al (1972) apud Morin, (1997, p.99) o sistema é "todo conjunto definível de componentes". Por seu turno, segundo entende Limberger (2006, p. 4) “(...) Apesar de variarem as definições, normalmente encontram-se presentes as características principais de um sistema, como o caráter global, o aspecto relacional, a organização, a hierarquização (...)". Neste mesmo sentido, ressalta-se, segundo este autor, a proposição de Morin (1997, p. 99) que define de forma muito precisa e concisa o sistema como: “(...) uma totalidade organizada, feita de elementos solidários que só podem ser definidos uns em relação aos outros em função de seu lugar nesta totalidade (...)".

Tais sistemas concebidos pelos autores supracitados podem ser compreendidos e classificados em isolados e não isolados. Para tal classificação, se entende por sistemas isolados aqueles onde não se dá trocas de energia e matéria com outros sistemas; por sua vez, os sistemas tidos como não isolados são caracterizados pela troca de energia e/ou matéria, sendo que, existe uma subdivisão entre sistema não isolado fechado e aberto, sendo que no primeiro ocorre apenas troca de energia e no segundo energia e matéria (CHRISTOFOLETTI, 1999).

Nesta perspectiva Christofoletti (1979) apud Limberger (2006) entende que a matéria, energia e estrutura compõe o sistema, onde a matéria seria caracterizada pelo material que será mobilizado através do sistema. A energia seria caracterizada pela força que faz compõe o sistema funcionar. A estrutura responderá pelos elementos e suas relações. A compreensão de sistema preconiza o que Morin (1997) identifica como "um e múltiplo", uma vez que o 
sistema embora seja identificado como um, é também múltiplo, podendo ser analisado em diversos subsistemas.

Na Geografia Física a TGS foi amplamente empregada em pesquisas desenvolvidas na área de Geomorfologia e nos estudos integrados da paisagem que em suas análises utilizaram o conceito de geossistema proposto por Sotchava (1977); onde o geossistema é compreendido como "formações naturais, experimentando, sob certa forma, o impacto dos ambientes social, econômico e tecnogênico" (SOTCHAVA, 1977, p. 9).

Obviamente, os estudos desenvolvidos no campo da Geografa Física não podem, de forma alguma, estar dissociados dos aspectos antropogênico presentes no ambiente (recorte espacial) considerado.

\section{ABORDAGEM SISTÊMICA E GEODIVERSIDADE: GEOGRAFIA E SOCIEDADE}

As discussões acerca da Geodiversidade iniciaram-se provavelmente a partir da convenção de Malvern realizada no Reino Unido no ano de 1993 com a temática "Conservação Geológica e paisagística" (NASCIMENTO; RUCHKYS; MANTESSO-NETO, 2008). Embora segundo Gray (2013) os princípios por detrás de sua aplicação para a conservação do meio natural sejam mais antigos, remetendo a exemplos como o relatório do Comitê Especial para Conservação da Vida Silvestre de Julian Huxley em 1947. Com o marco de Malvern, posteriormente, estudos nesta área foram incentivados e a nomenclatura começou a aparecer em documentos oficiais de nações, como é o caso da Austrália em 1996, onde a Geodiversidade é citada ao lado da biodiversidade nas diretrizes de conservação de sítios naturais.

Embora os estudos em Geodiversidade sejam relativamente recentes, diversos autores brasileiros e internacionais contribuíram para a construção de um edifício conceitual robusto e extremamente coeso. Gray (2004) apud Gray 
(2005) admite a Geodiversidade como o componente abiótico da biodiversidade, podendo ser determinada como a variante natural (diversidade) de feições geológicas (rochas e minerais, fósseis) e geomorfológicas (paisagens, processos e de solos). Incluindo ainda suas composições, relações, propriedades, interpretações e sistemas. (GRAY, 2004 apud GRAY, 2005) e o acréscimo social e cultural proposto por Stanley (2000) de que a Geodiversidade abranja mais que os recursos abióticos do planeta, relacionando ainda os seres humanos e a paisagem constituída.

A pesquisa em Geodiversidade além de identificar as localidades de valores relevantes para preservação, possibilita também uma compreensão sistêmica sobre a influência de cada elemento que compõe a diversidade abiótica local em seu contexto específico, levando em consideração cada elemento natural e antrópico presente. Aliás, a compreensão de que a excepcionalidade local se encontra sempre condicionada a processos de origens múltiplas e condições únicas é que conferem às pesquisas situadas neste campo uma abordagem ampla e sistêmica.

A percepção de sistemas embora abstrata se abordada de forma teórica, pode ser facilmente compreendida como a exemplo de uma bacia hidrográfica (sistema não isolado do tipo aberto), a qual possui diversas micro realidades no decorrer do curso do corpo hídrico. Entretanto, a dinâmica do curso d'água se dará em funções distintas levando em consideração outros elementos como a inclinação do terreno, a permeabilidade do solo/rocha do curso hídrico, a porcentagem de vegetação ciliar ao longo do curso, ao deslocamento de sedimentos etc. Toda essa complexidade de variáveis presentes em um só sistema poderá ser expressa em uma fração menor da bacia, entretanto, as micro realidades, se compreendidas isoladamente e depois somadas como propunha o cartesianismo, poderá indicar uma diferença imensa da realidade do objeto, uma vez que as relações presentes não foram levadas em consideração. 
Para além das análises naturais, pode-se também exemplificar a dinâmica antropogênica tendo como exemplo o trecho de uma bacia que se encontra inserido em um contexto urbano, onde padeça com a poluição, pois, ao ser submetida ao método cartesiano, seria percebido a concentração de poluentes presentes na água, mas as relações internas seriam desconsideradas. Desta compreensão de que as partes se somadas não são capazes de explicar a totalidade é que Bertalanffy (1973) entende que a totalidade é superior à soma das partes.

Tendo essa compreensão, os estudos em Geodiversidade assim como o exemplo da bacia hidrográfica, buscam levar em consideração em suas análises qualitativas e quantitativas todos os elementos do meio abiótico que compõem uma totalidade. Nestes estudos são levados em consideração principalmente a hidrografia, a pedologia, o clima, a geologia, a paleontologia e a geomorfologia de forma a compreender o quão diversa é a localidade.

Em consonância com a identificação e compreensão da Geodiversidade, deve-se frisar a contribuição proporcionada pela mesma à sociedade, a qual pode compreender o espaço vivido como uma fonte histórica de tempos remotos, pois, a busca pela preservação dos geopatrimônios coopera com a preservação da identidade dos indivíduos residentes das áreas circunvizinhas, apresentando um contraponto às transformações que as atividades antropogênicas fazem na incorporação do mesmo.

Eberhardt (1997) apud Sharples (2002) entende que o geopatrimônio é formado pelos elementos da Geodiversidade que possuem relevância para a humanidade por diferentes razões que não se circunscrevem apenas à extração de recursos, devendo ser preservadas para benefício das futuras gerações (BORBA, 2011, p. 6). Nesta perspectiva, é notório que a atenção dedicada pelas pesquisas que se ocupam com a Geodiversidade objetiva a preservação das áreas com valores singulares para a história do planeta e da humanidade. 


\section{A ABORDAGEM SISTÊMICA E A PESQUISA}

A abordagem sistêmica tem em seus pilares conceituais a compreensão de totalidade do sistema e as relações interpostas entre os elementos que o compõem. Para a realização das pesquisas nas quais este método é empregado, faz-se necessária uma estratégia específica bem como práticas que busquem analisar de forma holística o meio natural no caso da Ciência Geográfica.

Neste entendimento, as práticas sugeridas no ensaio deste artigo constituem respectivamente o geoprocessamento aplicado a sobreposição de mapas com o propósito de destacar os elementos da Geodiversidade e o trabalho de campo, pois articulando esta primeira prática com o objeto podemos conceber mapas do tipo coropléticos ou mesmo do tipo kernel de informações extraídas de shapes sobrepostos dos elementos da Geodiverdade.

Um exemplo que contribui e auxilia na compreensão desse procedimento é encontrado na metodologia proposta por Pereira et al (2013) contemplando a totalidade abiótica (Figura 1) através dos dados das formações geológicas, das formas de relevo, hidrografia, pedologia e clima, mediante a sobreposição de cada shape contemplando ainda a contabilização por cada quadrante determinado pelo autor em sua área de estudos (no caso de $2 \mathrm{~km}^{2}$ ).

Entretanto, embora as pesquisas em Geodiversidade utilizem de práticas quantitativas e de geoprocessamento, nem sempre os dados obtidos nesta interpolação retratarão o cerne da pesquisa. Muitas das vezes as localidades com maiores índices de Geodiversidade não apresentarão necessariamente sítios excepcionais, por isso a compreensão qualitativa deve sempre ser atrelada a pesquisa e a compreensão sistêmica para não perderem a qualidade e não apresentarem equívocos de interpretação e análise. 
Figura 1: Imagem da metodologia de Pereira et a/(2013)

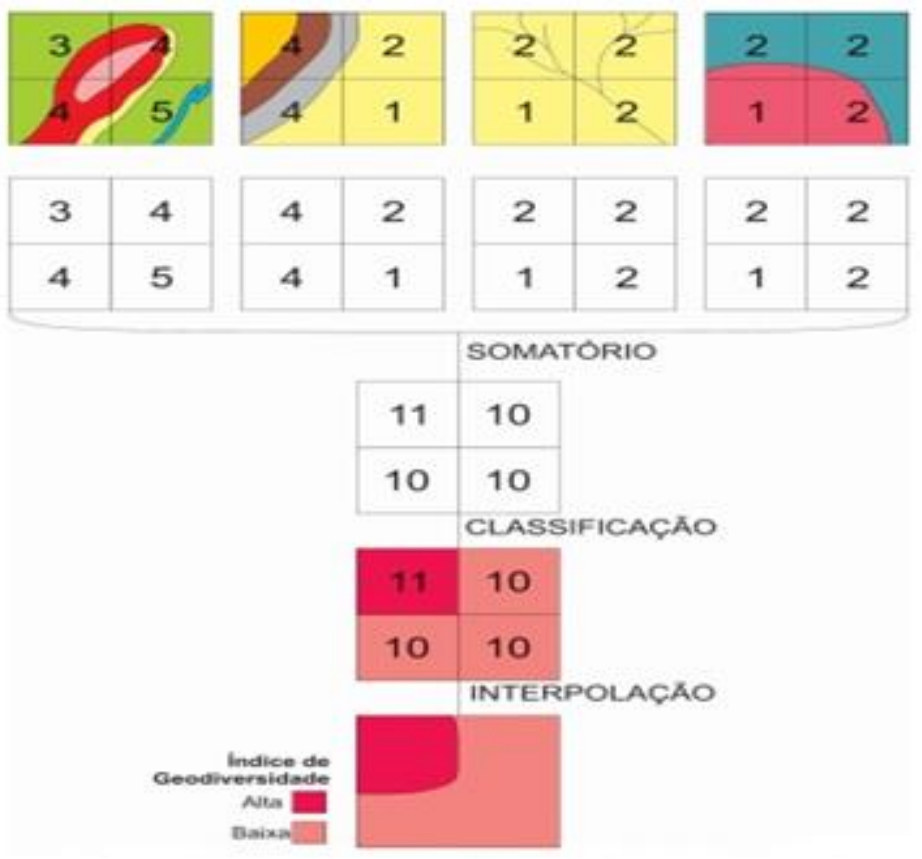

Fonte: Silva (2018)

No que concerne ao trabalho de campo, Anghinone et al (2020) explicita que o mesmo se inicia pela fase exploratória, ocupando-se com a caracterização do impacto a ser avaliado, do objeto, dos pressupostos, teorias e do percurso metodológico. O mesmo não tem como finalidade inicial a resolução do problema, mas sim caracterizá-lo a partir de uma concepção geral.

A ida a campo está presente em toda a história da Ciência Geográfica, sendo sempre considerada como primordial para se fazer uma análise concisa do espaço e suas relações (LIMBERGER, 2006). No tocante a Teoria Geral dos Sistemas e a Geodiversidade, esta visita se torna indispensável, uma vez que as localidades passíveis de identificação e proteção, devem ser analisadas com ações qualitativas e quantitativas. É neste momento da pesquisa que se compreende a magnitude da feição, seu grau de importância para a história da Terra e/ou humanidade, necessidade de intervenções, se é possível a abertura para visitações e qual as especificidades a serem seguidas para tal.

Não se restringindo somente às observações de cunho qualitativo, a 
análise em campo tem como finalidade compreender a totalidade dos eventos. Estas práticas além de nortear as pesquisas na Geografia Física, são sem dúvidas a sua maior fonte de dados, uma vez que a realidade observável é mais conclusiva que a bibliografia estudada na maior parte das vezes. Portanto, é preciso conceber também que a observação em uma escala de maior detalhamento pode conter especificidades chaves para o estudo de toda uma área que sem sombra de dúvidas poderia passar despercebidas em análises bibliográficas.

Compreende-se, portanto, que sob a ótica de uma pesquisa em Geografia Física que trabalhe com a abordagem sistêmica, ambas as práticas sugeridas neste artigo, contribuem para seu desenvolvimento e compreensão, sendo o geoprocessamento um grande aliado na construção de uma base quantitativa e de localização para a pesquisa, de forma a proporcionar materiais base e produtos finais quando associados às análises qualitativas. Já o trabalho de campo por sua vez se mostra indispensável para o reconhecimento do meio em análise, dos elementos inerentes ao sistema, sua dinâmica e excepcionalidade.

Portanto, tornam-se fundamentais a soma do geoprocessamento alimentado por atividades de campo como as visitas empíricas à área de estudo, conferindo informações e buscando a identificação de elementos da Geodiversidade e/ou áreas que permitam seu enquadramento enquanto geopatrimônio. Em tais visitas, procede-se as inventariações in situ com análises e catalogação dos lugares e componentes, mediante, por exemplo, a metodologia de Gray (2004) apud Gray (2005), que possui por referência os parâmetros da Geodiversidade. Para além das análises, são retiradas fotografias comprobatórias e feita a coleta de amostras, tanto petrográficas como mineralógicas para posterior análise. Como resultado, um banco de dados muito bem detalhado é organizado para impedir equívocos observadas 
em catálogos e imagens, conferindo credibilidade ao material elaborado através do geoprocessamento.

Obviamente, a análise das informações colhidas no trabalho de campo e na verificação das imagens disponíveis sobre uma determinada área de estudo, deve estar pautada pelos parâmetros já estabelecidos por cada campo do conhecimento que se debruça sobre um determinado componente da paisagem para posterior soma, numa avaliação da totalidade que se encontra estabelecida na paisagem e mantém constante interação, inclusive, com os elementos antrópicos que já promoveram a alteração parcial do espaço através das intervenções que foram efetuadas pelo homem na incorporação e uso do solo e demais recursos naturais.

\section{ESTUDOS DE GEODIVERSIDADE E SUAS APLICAÇÕES}

Os estudos em Geodiversidade são recentes, remetendo-se à década de 1990, entretanto, diversos autores brasileiros e internacionais contribuíram para a construção de um edifício conceitual robusto e extremamente coeso. Esta pesquisa sustenta-se sob a definição de Geodiversidade empregada por GRAY (2004 e 2005), na qual é definida como o equivalente abiótico da biodiversidade, podendo ser identificada como componente (diversidade) das feições geológicas (rochas, minerais e fósseis) e geomorfológicas (paisagens, processos e solos); incluindo suas composições, interações, características, variedade e sistemas (GRAY, 2004 apud GRAY, 2005, p.5). Bem como os aspectos acréscimo social e cultural propostos por Stanley (2000, p.15) ao entender a Geodiversidade mais abrangente que somente os recursos abióticos do planeta, consistindo também na ligação entre pessoas, paisagens, recursos e suas culturas.

Todas essas contribuições acerca da Geodiversidade têm sua origem na convenção de Malvern ocorrida no Reino Unido no ano de 1993 com a temática 
"Conservação Geológica e paisagística" (NASCIMENTO; RUCHKYS; MANTESSONETO, 2008). Embora segundo GRAY (2013) os princípios por detrás de sua aplicação para a conservação do meio natural sejam mais antigos, remetendo a exemplos como o relatório do comitê Especial para conservação da vida Silvestre de Julian Huxley em 1947. Com o marco de Malvern, posteriormente, estudos nesta área foram incentivados e a nomenclatura começa a aparecer em documentos oficiais de nações, como é o caso da Austrália em 1996, onde a Geodiversidade é citada ao lado da biodiversidade nas diretrizes de conservação de sítios naturais.

A busca pela emancipação do conceito de Geodiversidade ao da biodiversidade se deve ao vínculo intrínseco entre ambos, sendo que o primeiro por sua vez abrange a diversidade dos elementos bióticos. Segundo Garcia (2014) em consonância com a Royal Society for Nature Conservation/UK em 2000, a Geodiversidade é fundamental para a evolução e incrementoo da biodiversidade e do homem, uma vez que fornece elementos químicos para o seu desenvolvimento e é o substrato onde se dão todas as coisas, muito embora este conceito ainda seja recente em relação ao supracitado.

Como geodiversidade, entende-se a variedade de ambientes geológicos, fenômenos e processos ativos geradores de paisagens, rochas, minerais, fósseis, solos e outros depósitos superficiais que constituem a base para a vida na Terra. (Royal Society for Nature Conservation - GUERRA, 2018 apud Stanley, 2000, p. 32).

Adotando a mesma concepção manifesta pela Royal Society for Nature Conservation, a Companhia de Pesquisa de Recursos Minerais do Brasil faz uso dessa conceituação para Geodiverdade em um livro elaborado por Silva (2008). É sobremodo importante salientar que inerentes ao conceito de Geodiversidade, alguns subconceitos destacam-se, sendo todos conglomerados partícipes da 
geodiversidade, tais como: Patrimônio Geológico, Patrimônio Natural, Patrimônio Geomorfológico, Geossítios, etc. Embora ocorra compreensões errôneas, a geodiversidade se apresenta como um conjunto mais amplo que os subconceitos supracitados, nos quais esses se inserem (Nascimento et al. 2008).

Referindo-se ao patrimônio geológico, o mesmo é categorizado e entendido por Brilha (2005) como:

O conjunto de geossítios de um local, delimitado geograficamente, onde ocorrem elementos de geodiversidade, com valores singulares do ponto de vista científico, pedagógico, cultural ou turístico. É constituído por todos os recursos naturais não-renováveis, quer sejam formações geológicas ou geomorfológicas, paisagens, afloramentos mineralógicos e paleontológicos (Brilha, 2005, p. 23).

Conforme o autor supracitado, o patrimônio geológico constitui um vasto conjunto que abrange de forma eficiente os componentes de maior relevância que acabam por constituir a Geodiversidade, tais como: o patrimônio mineralógico, geomorfológico, petrográfico, hidrológico, paleontológico, entre outros. Por seu turno, o geossítio é compreendido como a manifestação de um ou mais constituintes da Geodiversidade que se apresentam na superfície, resultando dos processos naturais ou mesmo da interferência antrópica, localizado no espaço geográfico e com importância singular sob a perspectiva científica, pedagógica, cultural, turística ou outra qualquer (BRILHA, 2005).

Eberhardt (1997 apud Sharples, 2002) entende que o patrimônio geológico ou o geopatrimônio é formado pelos constituintes da Geodiversidade que são relevantes para a humanidade por razões que estão além da pura e simples exploração ocupada com a geração de riqueza, pela importância que podem assumir para as próximas gerações (BORBA, 2011, P.6). É perceptível que o enfoque de grande parte das pesquisas que envolvam a geodiversidade fitem-se na busca pela preservação das áreas com valores singulares para a história do 
planeta e da humanidade. É neste sentido que o conceito de Geoconservação é concebido.

Na literatura, inúmeras são as atividades geoconservacionistas ocorridas antes da definição concreta do conceito, tais como a proteção da caverna de Baumann, na Alemanha em 1668, a Hutton's Rock, em Salisbury Crags, Edimburgo na Escócia e a criação do Parque Nacional de Yellowstone em 1872 (Guerra, 2018). Entretanto, o conceito de geoconservação aparece robustamente na obra de Sharples em 2002, na qual é proposto o entendimento de que a geoconservação objetiva a preservação/proteção da Geodiversidade relacionada às feições geológicas, geomorfológicas e pedológicas de forma a garantir a manutenção da história de sua evolução em termos de velocidade e magnitude.

Em concordância com Sharples (2002), Worton (2008) definiu que a geoconservação abrange as intenções e iniciativas implementadas com o propósito de preservar e proteger a variedade geológica em proveito das gerações futuras. Brilha (2005) também oferece sua contribuição, argumentando que a geoconservação favorece o uso sustentável da Geodiversidade, incluindo o patrimônio geológico.

Brilha (2005) também recomenda a realização de seis estágios como requisito básico para a promoção da geoconservação de determinado local, sendo o primeiro deles: O inventário (ferramenta utilizada para reconhecer o valor patrimonial dos bens), é uma etapa também indicada por Gray (2004), pois coopera com a valoração da Geodiversidade e o necessário reconhecimento da excepcionalidade que o sítio possui. O segundo estágio proposto por Brilha (2005) é a quantificação do sítio, isto é, a busca pela materialidade traga pela análise quantitativa da relevância da localidade usando parâmetros de pontuação por atribuição de notas e estabelecimento rankings comparativos (GUERRA, 2018).

O terceiro estágio refere-se à classificação (enquadramento das 
localidades singulares na legislação de proteção). Inoportunamente o Brasil não possui uma estrutura específica para gerir e fiscalizar a proteção do patrimônio geológico e da Geodiversidade, entretanto, a lei federal n 9985 de 2000 atribui a gestão de tais localidades ao Sistema nacional de Unidades de conservação. O quarto estágio é a conservação, que pressupõe a busca pela manutenção da integridade do geossítio, podendo incluir restrições de uso e até a implantação de barreiras físicas visando a conservação local. A Valorização e divulgação configura o quinto estágio para promoção da geoconservação no qual, as ações executadas devem demonstrar a importância da localidade por meio de estratégias diversas. Neste estágio é importante salientar a importância desempenhada pelo geoturismo para a proteção dessas localidades, uma vez que a sociedade deve fazer parte do processo de proteção.

Segundo Guerra (2018), a geoconservação depende do apoio da sociedade para se concretizar, entretanto, este apoio somente será obtido se houver entendimento da real importância destes lugares, o que de certa forma, pressupõe a absorção de informações e conceitos básicos pelos cidadãos que visitarão o possível sítio. O último estágio para uma efetiva geoconservação, Brilha (2005) propõe um monitoramento contínuo por parte do poder público visando o acompanhamento sistemático das interferências antrópicas e possíveis impactos, tais como a capacidade do local em receber turistas, sempre se objetivando a proteção das localidades detentoras de elementos da geodiversidade.

Outro conceito importantíssimo para estudos em geodiversidade é o de geoturismo, conceito esse proposto no ano de 1995 por Hose, todavia, ações de geoturismo são reconhecidas desde o século XVII, a exemplo de visitas de viajantes a cavernas e minas em Peak District no Reino Unido, o qual por este motivo é definido pela autora como berço do geoturismo. No Brasil a primeira utilização do termo ocorreu em 1970 com a publicação da cartilha geo-turística e 
rodoviária do estado do Rio de Janeiro (Guerra, 2018).

Hose (1995) fez sua primeira definição de geoturismo, categorizando-o como a provisão de serviços e facilidades interpretativas que possibilitam aos turistas a incorporação de informações específicas do sítio geológico e geomorfológico, em vez da simples e rasa apreciação estética; entendendo-o como a atividade que recobra instalações e serviços descritivos e informativos para geossítios, geomorfossítios e a topografia do entorno (incluindo artefatos in situ e ex situ associados), visando à sua conservação e gerando apreciação, aprendizagem e pesquisa para as gerações futuras.

Outros autores buscaram propor definições para o geoturismo, como Stueve, Cooks e Drew em (2002) e Arouca em (2011). Os primeiros, concebem o conceito supracitado como a combinação de atributos naturais e culturais, que fazem de certa forma com que determinado local seja distinto de outro, enfocando as características geográficas do destino (Nascimento; Mansur; Moreira, 2015). Arouca em consonância parcial com os autores em sua declaração, elaborada durante o Congresso Internacional de Geoturismo em Portugal compreende:

O geoturismo como o turismo que sustenta e incrementa a identidade de um território, considerando a geologia, ambiente, cultura, valores estéticos, patrimônio e o bem-estar de dos seus residentes (Arouca, 2011, p. 27).

Desta mesma forma, Newsome e Dowling (2006) compreendem que o geoturismo relaciona geologia, geomorfologia, recursos naturais e seus processos de evolução com o turismo, que por sua vez, envolve visitação, de modo a proporcionar nas pessoas um sentimento interesse, apreciação e entendimento. Esta dimensão de compreensão e apropriação do espaço e diversidade se dá no conhecimento, o que referenda a etapa de valorização e 
divulgação da Geodiversidade da localidade a ser analisada e inventariada, o geoturismo por sua vez pode ser um promotor tanto da divulgação quanto da geoconservação.

Segundo Guerra (2018) o turismo e o geoturismo são relevantes estratégias de incremento econômico dos lugares, uma vez que desempenham papéis importantes nos projetos e usos da Geodiversidade com valores especiais, pois podem induzir o desenvolvimento local por meio de ganhos diversos como: hospedagem, gastronomia, compras de produtos. Esta modalidade de turismo recobra a conservação do bem, se diferenciando do turismo predatório que gera degradação e pode levar à perda do bem o desinteresse da futura visitação.

\section{CONSIDERAÇÕES FINAIS}

Mesmo que o presente trabalho não tenha tido o objetivo de apresentar uma aprofundada discussão e reflexão sobre o tema apresentado, trouxe uma importante contribuição para a Ciência Geográfica, através do diálogo mantido entre a abordagem sistêmica, a Geodiversidade e práticas de pesquisas; contribuindo ainda com os estudos que se ocupam com o espaço e a paisagem em seus diferentes recortes territoriais.

Tal entendimento advém do destaque feito à necessidade de se compreender o espaço de forma mais complexa e sistêmica, respeitando suas particularidades sem contudo ignorar a interação que mantém e toda a dinâmica que constrói através de uma totalidade que precisa ser analisada, pois, a contribuição proporcionada pelo cartesianismo ao enfatizar que o todo sempre é indicado pela soma das partes não é mais suficiente para abarcar a totalidade das relações dadas no espaço, tornando assim as análises superficiais em contraposição à realidade complexa e interligada. 
Sem a compreensão da conjuntura estabelecida por uma totalidade e o seu tratamento enquanto objeto de análise, fica comprometida toda pesquisa que se desenvolve numa determinada localidade contemplando os elementos constituintes que lhe moldam uma feição, pois estão em interação que promove complexidade além daquela que se observa na particularidade isolada e influencia tanto o componente como o todo, demandando uma abordagem que esteja adequada para o nível de análise que passa a ser requerido.

Obviamente isso não implica em esvaziar os estudos específicos que se debruçam sobre determinados componentes da paisagem, sejam geológicos, geomorfológicos, botânicos, pedológicos, climáticos, hidrológicos ou antropogênicos, pois de suas contribuições é que se municia a análise da totalidade que constrói numa determinada localidade; na verdade, cuida-se em destacar a necessidade que existe de somar tais informações e dados de forma conjunta para aprofundar o entendimento do papel que exercem na totalidade e como diferenciam essas totalidades no mosaico da biosfera.

Isto posto, entende-se que a contribuição proporcionada por autores como Bertalanffy (1973) e Sotchava (1977) no advento de novas metodologias e enfoques para o estudo da paisagem e do espaço, torna-se significativa e emblemática para a Ciência Geográfica, qualificando suas pesquisas e ampliando sua compreensão da realidade dinâmica, permitindo a superação de paradigmas que dificultavam seu avanço e o ritmo das descobertas tão necessárias para a compreensão do espaço e das conjunturas que se estabelecem na medida em que as modificações transformam a paisagem.

\section{AGRADECIMENTO}

Ao Programa de Mestrado em Geografia da Universidade Federal de Alfenas - UNIFAL-MG pela oportunidade de aprofundar as práticas de pesquisa e 
avançar na caminhada acadêmica com a devida consistência e aprendizado.

\section{REFERÊNCIAS BIBLIOGRÁFICAS}

ANGHINONI, L. R. T.; MURARA, P.; DEON, A. R. A práxis no trabalho de campo: uma experiência em biogeografia. Geografia Ensino \& Pesquisa, Santa Maria, v. 24, e13, 2020.

AROUCA DECLARATION. International Congress of Geoturism, Arouca, 2011.

BERTALANFFY, L. V. Teoria Geral dos Sistemas. Tradução de Francisco M. Guimarães. Petrópolis: Vozes, 1973.

BORBA, A. W. Geodiversidade e geopatrimônio como bases para estratégias de geoconservação: conceitos, abordagens, métodos de avaliação e aplicabilidade no contexto do Estado do Rio Grande do Sul. Revista Pesquisa em Geociências, v.38, $\quad n^{0} 1 ; \quad$ p.3-14, jan/abr. 2011. Disponível em:http://www.pesquisasemgeociencias.ufrgs.br/3801/01-3801.pdf. Acesso em: Dez. 2020.

BRILHA, J.B.R. Patrimônio geológico e geoconservação: a conservação da natureza na sua vertente geológica. Braga: Palimage, 2005.190 p. Disponível em:< http://www.dct.uminho.pt/docentes/pdfs/jb_livro.pdf > Acesso em: Dez. 2020.

CHRISTOFOLETTI, A. Modelagem de Sistemas Ambientais. São Paulo: Edgard Blücher, 1999.

CHRISTOFOLETTI, A. Análise de Sistemas em Geografia. São Paulo: Hucitec, 1979. EBERHARD, R. Pattern and Process: Towards a Regional Approach to National Estate Assessment of Geodiversity; Technical Series, n. 2, Australian Heritage Commission \& Environment Forest Taskforce, Environment Australia, Canberra, 1997.

GARCIA, T. S. Da Geodiversidade ao Geoturismo: Valorização e divulgação do Geopatrimônio de Caçapava do Sul, RS, Brasil. Orientador: Prof. Dr. Adriano Severo Figueiró. 2014. 180 f. Dissertação (Mestrado em Geografia) - Centro de Ciências Naturais e Exatas, Universidade Federal de Santa Maria, Santa Maria, 2014. Disponível em: https://repositorio.ufsm.br/handle/1/9428. Acesso em: 28 dez. 2020. 
GRAY, M. Geodiversity: valuing and conserving abiotic nature. 2. ed. Chichester: John Wiley \& Sons, 508p., 2013.

GRAY, M. Geodiversity and Geoconservation: what, why, and how? Geodiversity \& Geoconservation, p. 4-12, $2005 . \quad$ Disponível em: http://www.georgewright.org/223gray.pdf. Acesso em: Mai. 2020.

GRAY, M. Geodiversity: valuing and conserving abiotic nature. John Wiley and Sons, Chichester, England. 434 p., 2004.

GUERRA, Antônio José Teixeira et al. Geoturismo, Geodiversidade e Geoconservação: Abordagens geográficas e Geológicas. 1. ed. Rio de Janeiro: Oficina de textos, 2018. 244 p. v. 1. ISBN 978-85-7975-300-8.

HOSE, T. A. Selling the story of Britain's stone. Environmental Interpretation, v. 10, n. 2, p. 16-17, 1995.

LIMBERGER, L. Abordagem Sistêmica e Complexidade na Geografia. Geografia. Revista do Departamento de Geociências da Universidade estadual de Londrina. Londrina: v. 15, n. 2, jul-dez, p. 95-109, 2006.

MATURANA, H. R., VARELA, F., FRENK, S. Size constancy and the problem of perceptual spaces. Cognition, v. 1, 97-104, dez, 1972.

MOREIRA, J. C. Geoturismo: uma abordagem histórico-conceitual: geotourism: an approach historical and conceptual. 2010. Disponível em: https://www.academia.edu/450787/GEOTURISMO_UMA_ABORDAGEM_HIST\%C3 \%93RICO_CONCEITUAL1. Acesso em: Dez. 2020.

MORIN, E. O Método: A Natureza da Natureza. Tradução de Maria Gabriela de Bragança. Mira-Sintra/Europa-América Ltda., 1997.

NASCIMENTO, M. A.; RUCHKYS, U. A.; MANTESSO NETO, V. Geodiversidade, geoconservação e geoturismo - trinômio importante para a proteção do patrimônio geológico. São Paulo: Sociedade Brasileira de Geologia, 2008.

NEWSOME, D; DOWLING, R. The scope and nature of geoturism. In: DOWLING, R; NEWSOME, D. Geoturism. Oxford: Elsevier, Butterworth; Heinemann, p. 3-25, 2006.

PEREIRA, D. I.; PEREIRA, P.; BRILHA, J.; SANTOS, L. Geodiversity Assessment of Paraná State (Brazil): An Innovative Approach. Environ. Manag., v. 52: 541-552, 2013. 
SHARPLES, C. Concepts and Principles of Geoconservation. Pdf document. Tasmanian Parks \& Wildlife Service website. 2002. Diponível em: http://www.dpiw.tas.gov.au/inter,nsf/Attachments/SJON57W3YM/\$FILE/geoconse rvation.pdf. Acessado em: 20/12/2020.

SILVA, M. L. N. Serviços Ecossistêmicos e Índices de Geodiversidade como suporte da Geoconservação no Geoparque Seridó. 2018. 177 f. Dissertação (Mestrado) - Curso de Geociências, Universidade Federal do Rio de Janeiro UFRJ, Rio de Janeiro, 2018.

SILVA, C. Geodiversidade do Brasil: conhecer o passado, para entender o presente e prever o futuro. Rio de Janeiro: CPRM, 2008.

SOTCHAVA, V. B. O estudo de Geossistemas. Métodos em Questão. São Paulo: USP/IG, n. 16, 1977.

STANLEY, M. Geodiversity. Earth Heritage. n. 14, 15-18, 2000.

STUEVE, A. M.; COOKS, S. D.; DREW, D. The geoturism study: phase 1 - executive summary, Washington: Travel Industry Association of America, 22 p., 2002.

VICENTE, L. E.; PEREZ FILHO, A. Abordagem Sistêmica e Geografia. Geografia. Rio Claro: v. 28, n. 3, p. 345-362, 2003.

WORTON, G. J. A historical perspective on local communities and geological conservation. In: BUREK, C. V; PROSSER, C. D (Ed). The history of geoconservation. London: The Geological Society of London, June 2008, p. 137146 (Special Publications, n.300). 